\title{
EVALUATION OF NANO CERAMIC COATING ON RADIOGRAPHIC DEFECTS OF THIN-WALLED AI4-1 ALUMINUM ALLOY SAND CASTING
}

\author{
Mansour Borouni ${ }^{1 *}$, Behzad Niroumand ${ }^{1}$, Mohammad Hossein Fathi ${ }^{1}$ \\ ${ }^{1}$ Department of Materials Engineering, Isfahan University of Technology, \\ Isfahan, 84156-83111, Iran
}

Received 20.07.2016

Accepted 28.09.2016

\begin{abstract}
Internal defects are among the problems in gravity casting of aluminum parts. The main internal volumetric defects are gas and shrinkage defects which form during solidification of the melt and drastically reduce the quality of the produced parts. These defects adversely affect the mechanical properties of thin walled castings parts. In this study, ceramic nanoparticles coatings were applied on the sand mold and the effect of mold coatings on the reduction of defects were investigated. X-ray radiography was used to detect defects in sand molds with ceramic nanoparticles coatings. For comparison, this test was performed on molds with micro-ceramic and graffiti coatings and uncoated sand mold. The results showed that the maximum amount of gas and shrinkage defects was observed in casting parts from AL4-1 alloy in uncoated molds. On the other hand, the minimum defects were found in molds coated with ceramic nanoparticles. It seems that the reduced defects in casting parts in molds coated with ceramic nanoparticles may be due to high thermal and chemical stability and higher heat transfer rate of the coating. These results can facilitate the production of high quality aluminum alloys parts using nanotechnology.

Keywords: AL4-1 Alloy, Nano-ceramic Coating, Thin-walled Parts, Gas Defects, Shrinkage Defect

\section{Introduction}

AL4-1 is an aluminum-silicon alloy which contains 9-10.5\% silicon ( $\mathrm{Si}), 0.25$ $0.35 \% \mathrm{Mn}$ and $0.23-0.3 \% \mathrm{Mg}$ according to National Standard of Russia, No GOST 1583-89 [1,2]. Due to the low density and good mechanical properties, this alloy has many applications in manufacturing thin-walled complex aircraft and aerospace parts.
\end{abstract}

* Corresponding author: Mansour Borouni, m.mahmoudsalehi@ma.iut.ac.ir 
Gas holes and shrinkage cavities are among internal defects arise during casting AL4-1 and adversely effect on properties of the parts [1-3].

The gas holes are round or extended holes with smooth walls that occur in clusters or dispersed forms across the casting part. Gas porosities are small holes which are usually distributed across the whole casting part thickness. In general, gas defects can be caused by mold moisture, the release of gas from molten metal or mechanical air confinement in the mold chamber $[4,5]$.

Shrinkage cavities are formed when feeding in a cross section of the casting part is insufficient and melt shrinkage is not fully compensated. Shrinkage cavities are appeared as dark areas with irregular dimensions and unknown shapes in the radiographic film. In contrary to gas holes, shrinkage cavities do not have smooth and shiny surfaces and have almost scattered dendritic surfaces. Depending on the solidification rate of the metal, shrinkage cavities can occur informs such as elongated holes, sponge and fibrous holes [5, 6]. Porous sponge is formed by feeding in alloys with long freezing range and the large enough thermal gradient but insufficient melt feeding [6]. Figure 1 shows the schematic view of porous sponge.

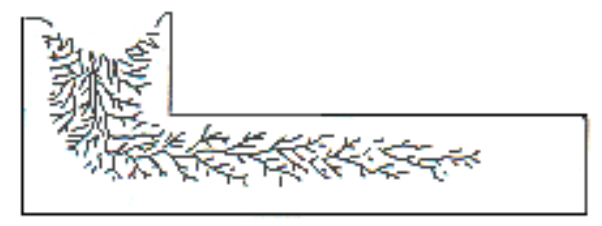

Fig. 1. Schematic view of porous sponge [6].

Among the factors affecting the formation gas and shrinkage defects are the casting ability and melt fluidity. The ability of a metal casting describes its ability to cast a defect-free part with the desired final properties [6]. It is noteworthy that different phenomena are associated with the casting ability of the melt such as mold filling, fluidity, feeding, porosity, macro segregation and hot tearing [7].

The fluidity is defined as the ability of molten metal flow in a standard mold before the end of solidification process [8]. Among the factors affecting the fluidity of the melt and quality of the casting part is type of mold coating. The coatings of casting molds are generally made of graphite and ceramic. Coating can affect the factors such as enhanced flow of melt into the mold and therefore easier mold filling and reduced friction coefficient of the mold. Surface tension is a harmful factor which ejects melt and prevents the filling of thin-walled molds with the thickness of 0.5 to $5 \mathrm{~mm}$. It acts like a repulsive force for melt and leads to decreased fluidity. The best way to reduce the effects of surface tension is to cover the surface of the mold which reduces the friction between the melt and mold wall by providing a smooth surface and reduced surface roughness of the mold. Some coatings improve fluidity through reactions that reduce the wettability of the melt/mold interface [9-13].

Common coatings used in the casting molds contain micron-sized or larger particles. Recent research has shown that particles with nanometer dimensions have different and generally better properties than micron-sized particles. The most common and most used nanoparticles are ceramic nanoparticles. Nano-ceramics particles or constitutes have a dimension less than about $100 \mathrm{~nm}$ [14]. It seems that nano-ceramic 
coatings on the mold surface have a more appropriate surface and much lower friction coefficient due to the low surface roughness. Also, because of high thermal and chemical stability due to ionic and covalent bonds of ceramic materials, nano-ceramic coatings have anti-stick properties which improves the surface quality of the parts casted in sand molds and improved mechanical properties due to the high surface quality of parts $[15,16]$.

In this study, the effect of applied ceramic nanoparticles coating on the surface of the sand mold in order to reduce internal defects of thin-walled aluminum alloy AL4-1 casting parts casted by gravity method was investigated. The parts were compared with casting parts using micron-sized ceramic coatings, conventional graphite coatings and uncoated molds.

\section{Experimental procedure}

In this study, aluminum ingots of, AL4-1 (AmizheSaz Arak) alloy were used. The chemical composition of the ingots was determined by optical emission spectroscopy (OES) method and is given in Table 1. For comparison, the standard chemical composition of this alloy is given in this table too. In each experiment, $180 \mathrm{~kg}$ of the alloy was melted in a resistance furnace with a graphite crucible. To perform qualitative operations on the melt, $0.05 \%$ beryllium $(\mathrm{Be})$ was added to the initial charge with the help of $\mathrm{Al}-5 \% \mathrm{Be}$ alloy. Melt fluxing was performed by a rotary degassing device for 10 min using a compound consisted of sodium chloride $(\mathrm{NaCl})$, potassium chloride $(\mathrm{KCl})$ and lanthanum fluoride $(\mathrm{LaF} 3)$. Finally, melt degassing was performed for 20 min using pure analytical grade argon (\% 999/99) with a flow rate of $11 / \mathrm{min}$ by rotary degassing device. Table 2 shows the chemical composition of the flux. This flux covers the surface of the molten aluminum, increases the melt purity and has some improvement effects on the eutectic silicon of the alloy. It also preserves the melt from the air and other chemical reactions [17-19].

Table 1. Standard and actual chemical composition of AL4-1 alloy [1, 2].

\begin{tabular}{ccc}
\hline Elements & Standard (wt \%) & Actual (wt \%) \\
\hline $\mathrm{Si}$ & $9-10.5$ & 10 \\
$\mathrm{Mn}$ & $0.25-0.35$ & 0.3 \\
$\mathrm{Mg}$ & $0.23-0.3$ & 0.3 \\
$\mathrm{Ti}$ & $0.08-0.15$ & 0.1 \\
Others & 0.6 & 0.6 \\
$\mathrm{Al}$ & Bal. & Bal. \\
\hline
\end{tabular}

Table 2. Chemical composition of the flux used in the present study [19].

\begin{tabular}{cc}
\hline Composition & Content (wt \%) \\
\hline $\mathrm{NaCl}$ & 45 \\
$\mathrm{KCl}$ & 45 \\
$\mathrm{LaF} 3$ & 5 \\
Other composition & 5 \\
\hline
\end{tabular}


Approximately 3 minutes before the end of degassing to have the best effect and minimize loss, $0.05 \% \mathrm{Sr}$ was added to the melt by $\mathrm{Al}-10 \% \mathrm{Sr} .0 .2 \% \mathrm{Ti}$ was added to the melt by Al-5Ti-1B while adding Sr. Titanium is added to the melt the end of degassing step to obtain fine grains with minimal loss.

Beryllium and strontium was added to improve the properties and melt fluidity. Beryllium protects the melt against oxidation and prevents prevent burning and wasting of active alloy elements like $\mathrm{Mg}$ [1,4]. Strontium modifies the eutectic silicon phase and optimizes the eutectic silicon phase and converts blade morphology into fibrous morphology tending to spherical morphology which improves the mechanical properties [20-22]. Furthermore, it is expected that Be would have an indirect role on melt fluidity while mold filling by reducing melt oxidation. It is also expected that $\mathrm{Sr}$ would have a useful role in increasing the melt fluidity and feeding range during freezing by modifying the morphology of the silicon blades.
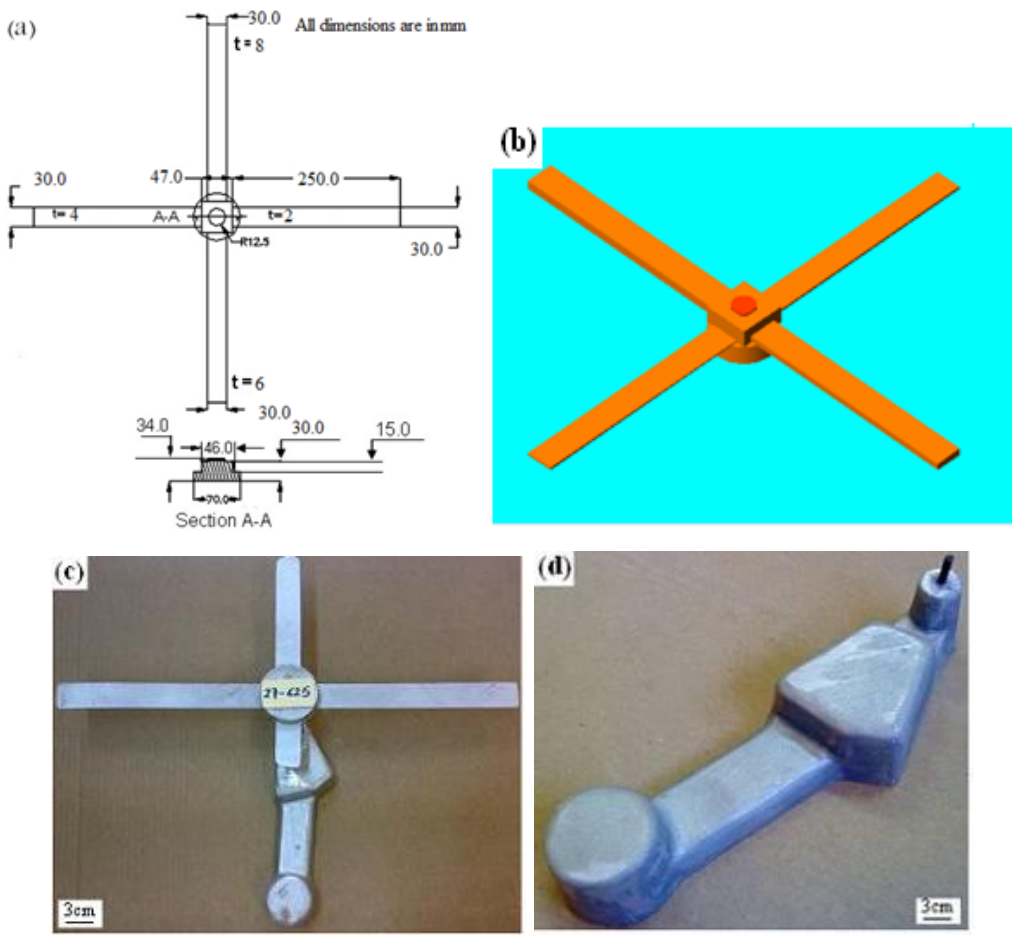

Fig. 2. a) The mechanical map of the pattern designed for fluidity test, $b$ ) threedimensional shape of the pattern, $c$ ) an as cast part and d) the two-cavity pouring basin designed according to AFS guideline [20, 23].

The casting pattern was designed and built as a four branches with different thicknesses of 2, 4, 6 and $8 \mathrm{~mm}$, with a width of $30 \mathrm{~mm}$ and a length of $25 \mathrm{~cm}$ to be close to the actual conditions of a casting part with different thicknesses. Figure 2 shows the three-dimensional view of a casting part by the mentioned pattern and the pouring cup (basin). A proper pouring cup (basin) was required in order to cast with a 
steady rate and carefully feeding with a minimum turbulence and error. The two-cavity basin was built according to American Foundry men Society (AFS) instructions [20].

Silica sand with $5 \mathrm{wt} \%$ sodium silicate binder was used to build the mold. Carbon dioxide blowing was used for hardening the mold. After building the mold, its surface was coated at room temperature by three types of coatings including a graphite coating manufactured by Fosico company (M100), a micro-ceramic coating (ZRI) manufactured by Radanco company and a nano-ceramic coating (MB12). The coatings were dried by natural gas such that the coating adheres well to the surface of the mold. Table 4 shows the chemical composition of the graphite coating.

Table 3. The chemical composition of the graphite coating used in the present study (wt\%)

$\begin{array}{cccccc}\text { Composition } & \text { Graphite } & \begin{array}{c}\text { Binder and } \\ \text { Resin }\end{array} & \begin{array}{c}\text { Suspending } \\ \text { agents }\end{array} & \begin{array}{c}\text { Other } \\ \text { refractories }\end{array} & \text { Water } \\ (\mathrm{wt} \%) & 85 & 5 & 5 & 5 & \text { Required amount }\end{array}$

To investigate the effects of mold coating on the quality of casting parts, the melt was casting in the molds at $625^{\circ} \mathrm{C}$ with different type of coatings presented in Table 4, after melt preparation and qualitative operations. To ensure the results, the casting was repeated 5 times for each sample. Casting samples have been inspected by radiography after cleaning. The influence of the coating on the incidence of internal defects including gas and shrinkage was investigated.

The type of micro and nanoparticles was studied by X-ray diffraction method. The approximate chemical composition of MB12 coating was determined by using inductively coupled plasma (ICP) spectrometer and energy dispersive spectroscopy. Table 5 shows the results. X-ray diffractometer (Philips $X^{\prime}$ pert-MPD) was used for phase analysis of coatings. It should be noted that following determining the chemical composition of MB12, a micron-sized coating with a same chemical composition with ZR1 produced by Radanco Company according to the order of authors.

The average grain size of phases was determined using the Scherer equation Eq. (1) $[24-26]$ :

$$
D=\frac{0.9 \lambda}{\beta \cdot \cos \theta}
$$

where $\lambda$ is wavelength (here, $0.15406 \mathrm{~nm}), \theta$ denotes diffraction angle and $\beta$ represents beam width (in radians) in the middle of the peak maximum. $\beta$ was calculated using the Eq. (2) [25]:

$$
\beta^{2}=\beta_{M}^{2}-\beta_{S}^{2}
$$

where $\beta_{M}$ is the beam width at the middle of maximum in the X-ray diffraction pattern of the nano-sized MB12 powder and $\beta_{S}$ is the beam width at the middle of maximum peak X-ray diffraction pattern of the micron-sized ZR1 powder sample. 
Table 4. Type of coating used on molds for casting specimens [23]

\begin{tabular}{cr}
\hline Sample & Coating Type \\
\hline 1 & Uncoated \\
2 & Graphite \\
3 & Micron-sized ZR1 \\
4 & Nano-sized ceramic (MB12) \\
\hline
\end{tabular}

Table 5. The chemical compositions of MB12 and ZRI coatings used in the present study (wt\%) [23]

\begin{tabular}{cccccc} 
Composition & $\mathrm{Al}_{2} \mathrm{O}_{3}$ & $\mathrm{ZrO}_{2}$ & $\mathrm{SiO}_{2}$ & $\mathrm{H}_{2} \mathrm{O}$ & Others \\
\hline Content (wt \%) & 30 & 7 & 1 & 60 & 2
\end{tabular}

\section{Results and discussion}

Figure 3 (a) and (b) show scanning electron microscope (SEM) micrographs of micron-sized ZR1 and nano-sized MB12 coatings, respectively. The micron size particles in ZR1 coating and agglomerates composed of nano-sized particles in MB12 coating can be observed (Fig. 3). The micron-size coating with similar composition with nano-sized coating was used to evaluate the effect of particle size on the quality of casting parts.
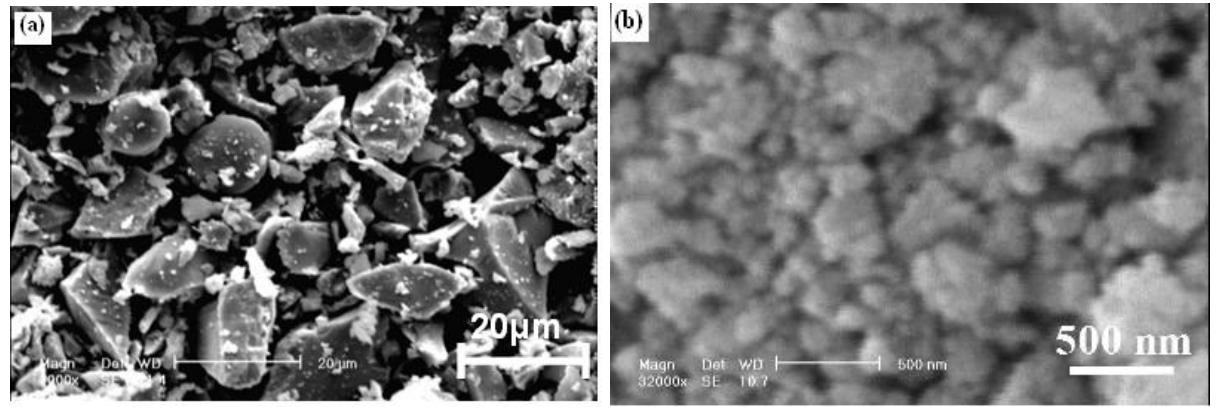

Fig. 3. Scanning electron microscope (SEM) micrographs of (a) ZR1 coating [23] and (b) MB12 coating.

Figures (4) and (5) show the XRD patterns of the nano-sized ceramic coating (MB12) and micron-sized ceramic coating (ZR1), respectively. According to the pattern shown in Fig. 4, the nano-sized ceramic coating (MB12) contains ceramic particles of $\mathrm{Al}_{2} \mathrm{O}_{3}, \mathrm{ZrO}_{2}$ and $\mathrm{SiO}_{2}$. The average grain sizes of phases were determined using the Scherer equation. According to X-ray diffraction pattern and APDW software, $\beta$ and $\theta$ can be calculated as follows:

According to the Scherer equation, the average grain size of $\mathrm{Al}_{2} \mathrm{O}_{3}, \mathrm{ZrO}_{2}$ and $\mathrm{SiO}_{2}$ phases in MB12 coating was about 30, 120 and $25 \mathrm{~nm}$, respectively. The melting point of bulk $\mathrm{Al}_{2} \mathrm{O}_{3}$ is $2015{ }^{\circ} \mathrm{C}$. Assuming that $\mathrm{Al}_{2} \mathrm{O}_{3}$ particles are single crystalline, their melting point would be similar to the bulk case, because the effect of particle size 
Sharifi et al. - Evaluation of nano ceramic coating on radiographic defects of thin-walled ... 199

on the melting point is important in the case where the particle size is less than $10 \mathrm{~nm}$. Therefore, it is not expected that sintering occurs during casting parts [27].

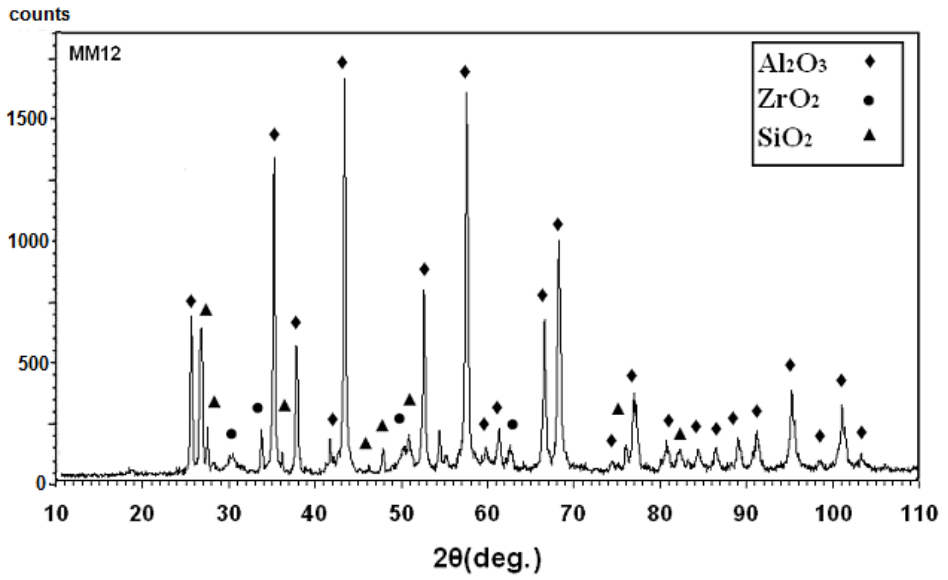

Fig. 4. XRD patterns of the nano-sized ceramic coating (MB12) [23]

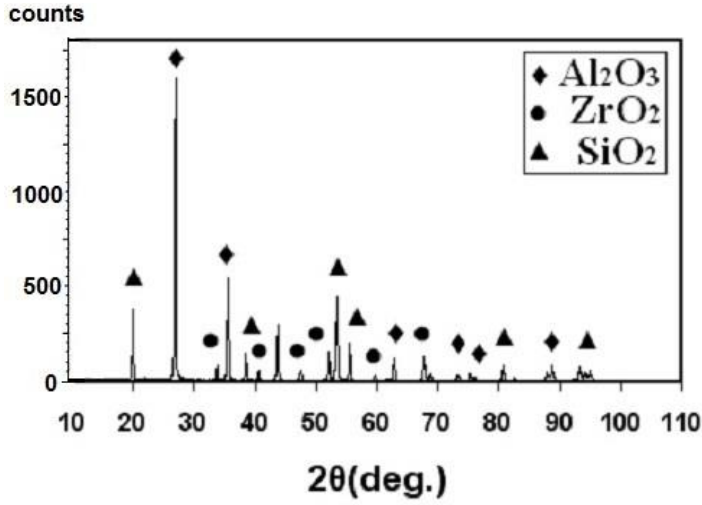

Fig. 5. XRD patterns of micron-sized ceramic coating (ZR1) [23]

Figure 6 shows some images taken by X-ray radiography from different regions of the casting samples in uncoated sand mold, graphite coated sand mold and sand mold coated with micron-sized ceramic coating. It should be noted that images (a), (b), (c), (e), (f), (g) and (h) shown in Fig. 6, belong to $8 \mathrm{~mm}$ sections of parts. Fig. 6 (d) shows the radiography image of a casting sample with a thickness of $2 \mathrm{~mm}$ in an uncoated sand pattern. 

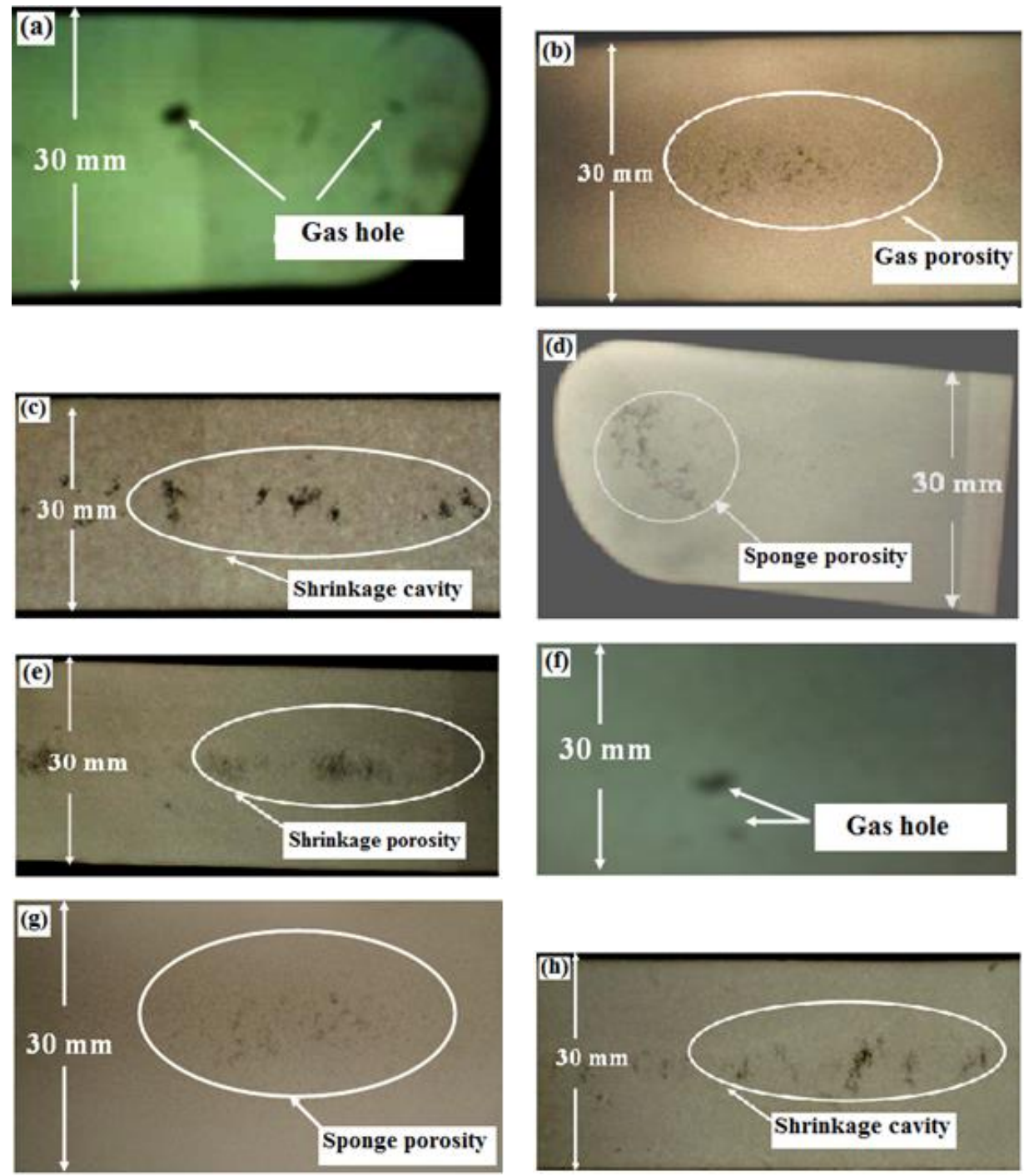

Fig. 6. The XRD radiography images of casting samples (a) to (d): uncoated sand mold, $(e)$ to $(g)$ sand mold coated with graphite and $(h)$ sand mold with micron-sized ceramic coating $(Z R l)$.

As can be seen in Fig. 6, all three samples have some gas defects including gas holes and porosities or shrinkage defects including shrinkage cavities and sponge porosities. Interestingly, most defects were observed in uncoated mold. In addition, no gas defects were observed in the parts casting in sand molds with a micro-ceramic coating. This trend was also noticed for shrinkage defects and most defects were observed in uncoated mold. The minimum defects were observed in the mold coated with micron-sized particles. 
Several studies [4-11] have shown that increasing the cooling rate of the part reduces shrinkage defects or leads to finer and more uniform distribution of shrinkage defects. The radiographic image of 6 (d) shows a casting sample with a thickness of 2 $\mathrm{mm}$ in an uncoated sand mold. The porous sponge defect occurs even in these thin sections obtained with uncoated mold. However, there are less defects with graphite coated mold or micron-sized ceramic coatings in section thinner than $8 \mathrm{~mm}$.

Figure 7 shows the radiographic X-ray images of two casting samples in the sand mold with nano-ceramic coating, MB12, with the thickness of $8 \mathrm{~mm}$. All mentioned internal defects cannot be observed in these images.
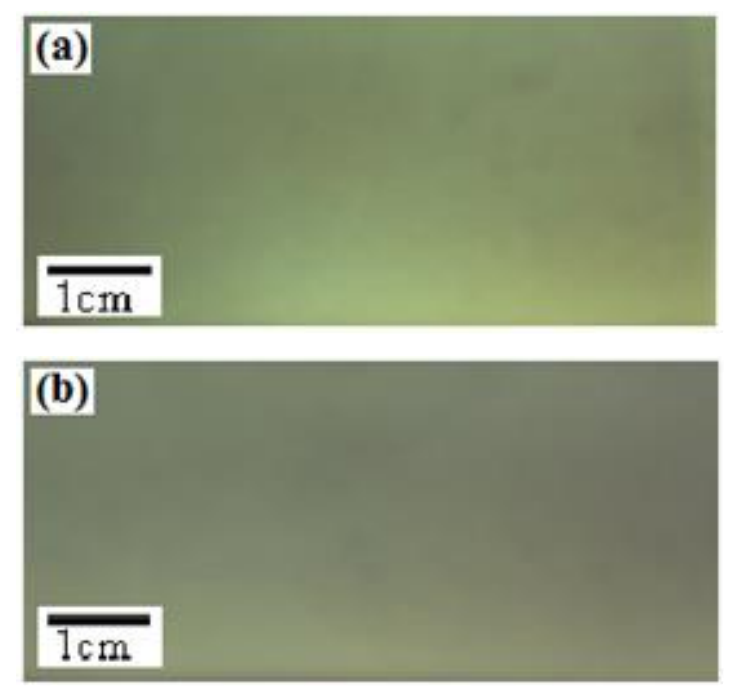

Fig. 7. The radiographic image of a cross section of $8 \mathrm{~mm}$ thickness casting in sand mold with nano-ceramic coating, MB12, (a) sample prepared from the beginning of the blade, and (b) sample from the end of the blade.

It seems that the reduction of gas defects by using graphite coatings and nanosized and micron-sized ceramic coatings is due to high thermal and chemical stability of ingredients in these coatings. These coatings are not reacting with the melt. In addition, they prevent the contact between the molten aluminum and molding material, reducing the reaction between these materials. On the other side, the reaction between the melt and partial moisture which exist in the molding material and gluing are prevented. This reaction leads to the oxidation of aluminum and the hydrogen is released in melt $/ \mathrm{mold}$ interface creating gas defects. Micro and nano-ceramic coatings will not produce gaseous products even at high casting temperatures and are superior than graphite coating in this regard.

The reduction of shrinkage defects using graphite, micro and nano-ceramic coatings can be attributed to their effect on the formation of oxide shells in the melt and the cooling rate of the melt. The smoothness and surface quality of the mold affect the melt fluidity and prevent the incidence of defects and cold sintering. However, since the shrinkage defects are basically formed after mold filling during solidification, it doesn't 
seem that the surface smoothness and roughness can directly affect melt feeding during solidification process.

Shrinkage defects mainly occur due to the lack of sufficient melt feeding at the end of solidification process [6]. The oxide phases which are formed by the direct contact of molten aluminum and mold moisture complicate melt feeding by closing the melt route in the dendritic network at the end of freezing. The used coatings can reduce the chemical reactions between the melt and molding material due to the high thermal and chemical stability [6].

Moreover, it seems that the applied coatings reduce shrinkage defects by increasing the cooling rate of melt. Even the ceramic coatings can lead to faster freezing because of high percentage of alumina which heat transfer coefficient is much higher than silica sands.

In the case of ceramic nanoparticles coatings, two other issues must be considered. First, the heat transfer from the melt is controlled by the gaseous layer created between the molt and surface roughness dents of the mold [28]. Each factor that reduces the thickness of the layer, increase the rate of heat transfer. For example, Ilkhchi et al [29] demonstrated that by applying pressure during freezing the melt, this gap is reduced and heat transfer further increases. Table 6 shows the mold surface roughness for different coatings. As can be seen, the surface roughness and the depth of surface roughness in the molds coated with ceramic nanoparticles is lower than the other samples. It is therefore expected that these coating have a higher contact surface area with the melt. It is also expected that the cryogenic power of the mold has a greater impact on the rapid freezing and the quality of casting part.

Table 6. The surface roughness of mold with different coatings

\begin{tabular}{lc}
\hline Mold Type & Surface Roughness $(\mu \mathrm{m})$ \\
\hline Uncoated sand mold & 7.3 \\
Sand mold with graphite coating & 6.8 \\
Sand mold with micro-sized coating, ZR1 & 4.7 \\
Sand mold with nano-sized coating, MB12 & 4.5 \\
\hline
\end{tabular}

The other factor which affects the contact surface area of the melt and mold is the wettability contact between them. Basically, molten metals have a big wetting angle with oxides $\left(>90^{\circ}\right)$. Several studies have shown that the wetting angle between solid and liquid surfaces is affected by surface roughness. The wetting angle increases for those surfaces that have a wetting angle greater than $90^{\circ}$ in fully flat state with increasing surface roughness [30]. This is shown in Fig. 8. In which $R_{f}$ is a measure of surface roughness and $\theta$ is the wetting angle. Accordingly, surfaces coated with nanometer particles have a smaller wetting angle; thereby such coatings have a greater contact surface area with the melt and cooling melt. 


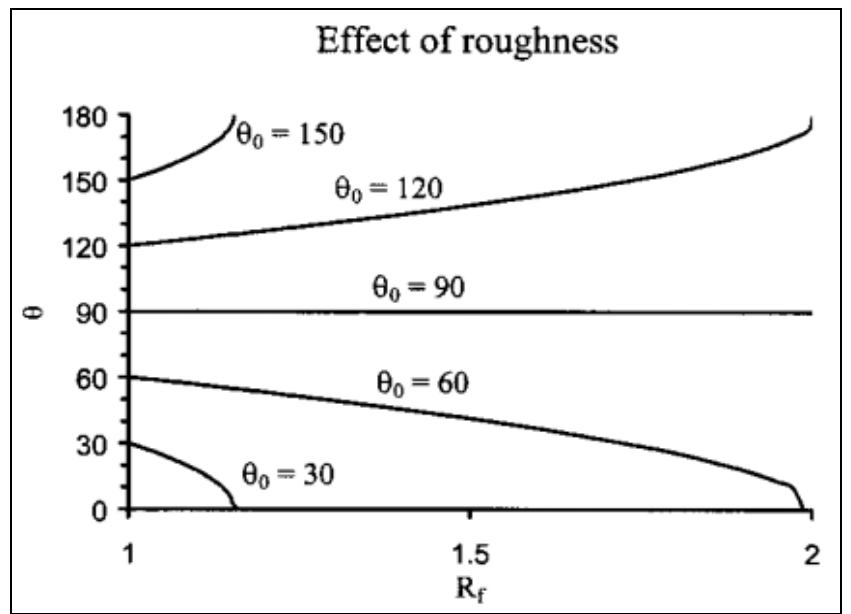

Fig. 8. The effect on the surface roughness on the wetting angle of a liquid/ solid surface [30].

\section{Conclusions}

In this study, the effect of different coatings type of sand mold on the internal defects of thin-walled aluminum casting parts was investigated by X-ray radiography method. The results showed that:

- The maximum amount of gas defects including gas holes and porosities and shrinkage defects including shrinkage cavities and sponge porosities were observed in parts casting in uncoated molds. The minimum defects were observed in the molds coated with ceramic nanoparticles such that the casting parts almost had no defects such as gases and shrinkage sources;

- It seems that the reduction of defects, with graphite coating molds and micronsized coating molds or nano-sized ceramic particles coating molds, is due to the high thermal and chemical stability and higher heat transfer rate of these materials compared to uncoated molding material;

- In the case of ceramic nanoparticles coating, it seems that the low roughness of the coating and the higher wettability of coating/melt would help the higher rate of heat transfer and the health of casting parts.

\section{Acknowledgments}

The authors are grateful for support of this research by Isfahan University of Technology (IUT).

\section{References}

[1] S. Vadim, A. Z. Nikolai: Casting Aluminum Alloy, first ed., Moscow Institute of Steel and Alloys-State Technical University, Elsevier Linacre House, Oxford, 2007.

[2] GOST 1583-89, "Aluminum casting alloys", Moscow, 1993. 
[3] R W. Osorio, R.L. Garicia, R.P. Goulart, A. Garcia: Mater Chem Phys, 106 (2007) 343-349.

[4] ASM Handbook Committee, Metals Handbook, Vol. 15, Casting, tenth ed., ASM International, 2008.

[5] Military standard, MIL-STD-2175A, "Castings, Classification and inspection", Department of defense, USA, 1993.

[6] J. Campbell, Castings, second ed., Elsevier Butterworth Heinemann publication, 2003.

[7] A.K. Dahel, L. Baeckrund and L. Arnberg: "Castability of Aluminum foundry alloys", Final report for AFS, 1997.

[8] M. C. Flemings, F. R. Mollard and H. F. Taylor: AFS Transactions, 69 (1961) 566576.

[9] M.D. Sabatino: "Fluidity of Aluminum Foundry Alloys", Ph.D. thesis, Norwegian University of Science and Technology, 2005.

[10] M.D. Sabatino, L. Arnberg: Metall Sci Technol, 22(2004) 9-15.

[11] K.R. Ravi, R.M. Pillai, K.R. Amaranathan, B.C. Pai, M. Chakraborty: J Alloys Compd, 456 (2008) 201-210.

[12] J. Campbell and R.A. Hardning: "The Fluidity of Molten Metals", Training in aluminum application technologies, TALAT Lecture 3205, Birmingham, 1994.

[13] P.R. Beely, Foundry Technology, Butterworth Scientific, 1972.

[14] N.A. Goldstein: Handbook of Nanophase Materials, Marcel Dekker Inc., 1997.

[15] G.J. Li, X.X. Huang and J.K. Guo: Mater Res Bull, 38(2003) 1591-1600.

[16] L. Feng, Y. Gencang: J Non-Cryst Solids, 290 (2001) 105-114.

[17] ASM Handbook Committee, Metals Handbook: Aluminum and Aluminum Alloys", ASM International, 1992.

[18] J.E. Gruzleski, B.M. Closset: The Treatment of Liquid Aluminum-Silicon Alloys, American Foundry men's Society, 1990.

[19] N. Hongjun, B. Sun, H. Jiang, W. Ding: J Mater Sci Eng A, 352(2003) 294-299.

[20] Metal caster's reference and guide, 1st. ed., American Foundry men's Society, 1972.

[21] D. Stuart, M. Donald, N. Kazuhiro, K. Arne, Dahle: J Alloys Compd, 442 (2006) 184-191.

[22] A.K. Prasada Rao, K. Das, B.S. Murty, M. Chakraborty: Mater Lett, 62 (2008) 273275.

[23] M. Borouni, B. Niroumand, M.H. Fathi: Materiali in tehnologije, 48 (2014) 473477.

[24] D. Delaportas, P. Svarnas, I. Alexandrou, A. Siokou, K. Black, J.W Bradley: J Phys D: Appl Phys, 42.24 (2009) 245204.

[25] B.D. Cullity, Elements of X-Ray Diffraction, second ed., Addison-Wesley, 1978.

[26] N. P. Prasad, Nano photonics, John Willey \& Sons Inc., 2004.

[27] J.Y. Huang: Nano Lett, 7 (2007) 2335-2340.

[28] A. Hamasaiid, M.S. Dargusch, C.J. Davidson, S. Tovar, T. Loulou, F. Rezaï-Aria and G. Dour: Metall Mater Trans A, 38 (2007) 1303-1316.

[29] A.F. Ilkhchy, N. Varahraam, and P. Davami: Iran J Mater Sci Eng, 9 (2012) 11-20.

[30] M. Nosonovsky. and B. Bhushan: Microsyst Technol, 11(2005) 535-549. 